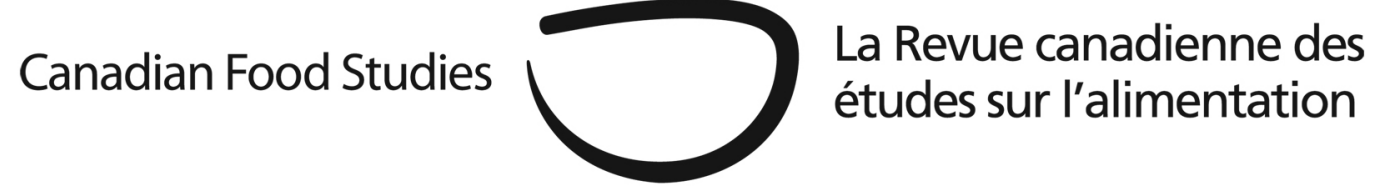

\title{
Perspective
}

\section{Rights for whom? Linking baby's right to eat with economic, social, and cultural rights for women}

Christina Doonan*

Memorial University of Newfoundland

\begin{abstract}
Breastfeeding women are primary food producers par excellence, delivering a custom-made product to fit the exact needs of a favoured clientele. The importance of breastmilk as a first food has been acknowledged in recent years by many states, which have taken measures to protect and encourage breastfeeding in acknowledgment of the World Health Organization's 2002 Global Strategy for Infant and Young Child Feeding. Within both state and grassroots efforts to promote it, breastfeeding is often framed in terms of "rights," though it is not always clear what these entail. This perspective article considers the role of breastmilk as a critical food for children that ensures their "right to the highest attainable standard of health" as articulated in Article 24 of the Convention on the Rights of the Child, and interrogates mothers' (and others') role in providing it. While food studies, and even more so, food security scholarship and activism should incorporate breastfeeding scholarship, it should avoid the mistake of framing breastfeeding as a “choice” made by individual women. This article advocates incorporating breastfeeding into the right to food/food security agenda by explicitly supporting measures that increase women's access to broader economic, social, and cultural (ESC) rights. This, in turn, would put breastfeeding within reach, as an option, for more women. Thus breastfeeding becomes more likely and pressure is diverted from individual mothers and the often false "choice" to breastfeed.
\end{abstract}

Keywords: breastfeeding; breastmilk; right to food; right to feed 


\section{Introduction}

A beautiful promotional poster for International Breastfeeding Week, 2000, pictures a breastfeeding baby enfolded securely in the arms of a mother, while suckling with placidly abstracted gaze (see figure 1). The text on the poster enjoins readers "Don't think of it as a woman's right to breastfeed. Think of it as a baby's right to eat.” Indeed, a great deal of attention to breastfeeding promotion has been, justifiably, to secure women's freedom to feed their babies publicly, even if the implement of meal delivery is a breast. But what is "baby's right to eat?" This slogan is helpfully provocative in gesturing toward several possible locutions for a probreastfeeding paradigm. Where does the nursing mother fit in to this equation and what is her relationship to baby's rights? What are her rights in breastfeeding? In this article, I argue that breastfeeding should be a central component of activism around the right to food and food security. Because the success of breastfeeding depends on a number of other economic, social and cultural

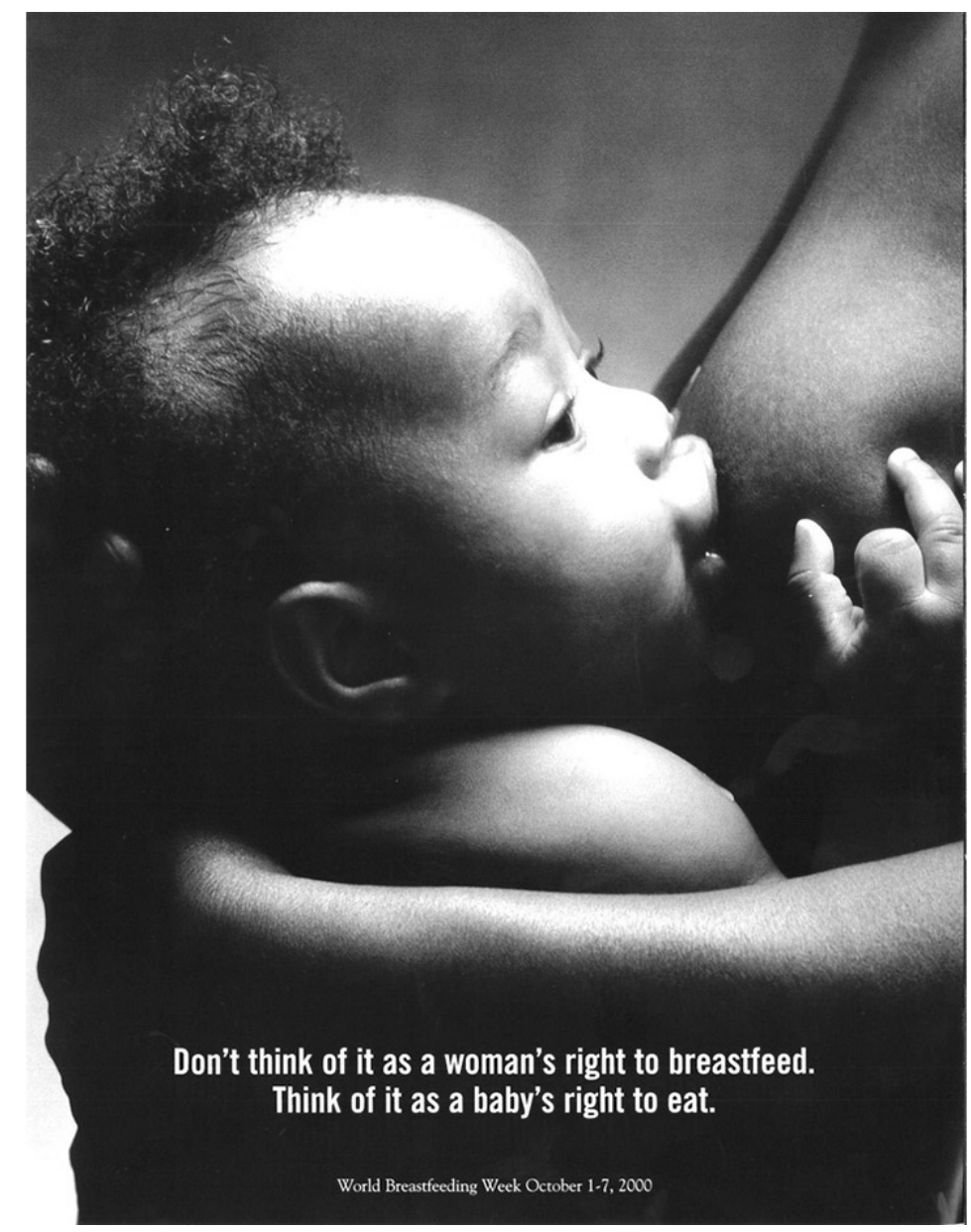

Figure 1:”Breastfeeding: It’s Your Right!” World Breastfeeding Week, October 1-7, 2000. From http://www.infactcanada.ca/mall/wbw2000.asp. Used with permission. 
(ESC) rights for women, this means that the food security/right to food agenda should encompass the promotion of a wide set of ESC rights that would increase women's access to breastfeeding as an option.

In the first section of this article I explain why, when we talk about breastfeeding in the context of rights, we should talk about access to breastfeeding as an option, rather than the right to breastfeed or to be breastfed. Second, I identify three entrypoints for integrating breastfeeding rights within the right to food and food security activism. These are: Van Esterik's "right to feed,” De Schutter's “right to food” and children's "right to health” as articulated in the Convention on the Rights of the Child . All three of these acknowledge the interdependence of food and health-related rights within broader ESC rights. After identifying the co-constitutive nature of these rights, I provide a brief overview of some of the most significant contemporary barriers to breastfeeding. These move far beyond a narrow focus on food, and yet they are a crucial foundation to food-based rights and food security. As such, they must become part of the food security and food rights agenda

\section{Giving breastmilk: From "choice" to "access"}

Because research confirms the benefits that derive from the uniqueness and complexity of human milk (e.g., German, Smilowitz, Lebrilla, Mills \& Freeman, 2015), there is a risk that mothers will be held morally responsible for their apparent "choices" around breastfeeding. To hold mothers solely responsible, however, ignores a number of barriers to breastfeeding for which the state and communities, rather than mothers, should be held to account. Often, despite the rhetoric of choice, mothers and parents simply do not have access to the possibility of breastfeeding. There may be physical, social, economic, or cultural barriers that prevent them from realizing the goal of breastfeeding, or even considering it in the first place. Therefore, ensuring ESC rights for women (including, for example, well-remunerated and extended maternity leave and thorough maternal health care) would increase the possibility of breastfeeding. Thus, the right to access breastfeeding as an option for the breastfeeding dyad (i.e. not mother or child, but the two in relation to each other) needs to be considered within a broader range of ESC rights.

"Access to breastfeeding” is a term that can apply to both mothers and babies equally rather than asserting baby's right against mother. I use the term "access” to suggest that breastfeeding is a good that could be chosen as an option under more equitable socio-economic conditions, although some may not choose it. Breastfeeding scholars have been careful to point out that "choice is a central tenet of the Western concept of the autonomous individual, and yet it’s often illusory” (Bartlett, 2005, p.160; see also Kukla, 2006; Murphy, 2003). Structural and economic factors loom large in determining whether a woman will be able to breastfeed (Galtry, 1997, p. 6), and disproportionately impact women from marginalized racial and economic groups (Taylor \& Wallace, 2012, p. 79). “Access to breastfeeding” was inspired by the pioneering 
thinker on food and feminism Penny Van Esterik's notion of the "right to feed." "Access to breastfeeding” recognizes women's agency while also respectfully assuming that most mothers love their children and want what is best for them, and that sometimes this involves feeding them breastmilk alternatives. Having acknowledged this, let us ask how the right to access breastfeeding intersects with food related rights? I turn to this question below.

\section{The web of co-constitutive rights}

The "right to food" is perhaps the most familiar articulation of food-related rights. As conceived by its best-known proponents, such as former UN Special Rapporteur Olivier De Schutter, the right to food typically considers the nutritional needs of older children and adults, and thus focuses heavily on agriculture in both its identification of vulnerable groups and its targeted solutions. For example, De Schutter (2009) identifies small-scale farmers, self-employed food producers, landless agricultural workers, and the urban poor as the most vulnerable groups when it comes to food insecurity (p. 40). He identifies rural development and support of agriculture as primary solutions for confronting this vulnerability (p. 40). Yet breastfeeding rates are below target virtually everywhere. The breastfeeding dyad (mother-infant) and support for access to breastfeeding as an option must be added to these lists if they are to be comprehensive.

Even while giving women due recognition as being particularly affected by food insecurity, De Schutter ignores the special role of lactating women's bodies as producing the only food product generated by the human body. His otherwise excellent thematic report on women and food only mentions lactation and breastfeeding in passing in the introductory paragraph (De Schutter, 2012, p. 3). This is a particularly surprising omission considering his acknowledgment that "between one fifth and one quarter of child deaths can be attributed to low birth weight and childhood underweight.” (De Schutter, 2011a, p. 305). Encouragingly, De Schutter has elsewhere noted the likelihood that infant formula predisposes children to obesity and diabetes and, in recognition of the pernicious effects of multinational food companies' marketing of formula, he has called on countries to implement the "full set of WHO recommendations on the marketing of breast-milk substitutes and of foods and non- alcoholic beverages to children, in accordance with WHA resolution 63.14.” (De Schutter, 2011b, p. 10). Indeed, breastfeeding may be seen as a cornerstone of food security in that it is a "first food" with tremendous benefits to infants; it does not require packaging and shipping and is therefore not dependent upon food delivery infrastructure, nor is it environmentally harmful. ${ }^{1}$ It may be a definitive element that sets the course of individual eating habits. Thus, empowering not only agriculture and agricultural producers, but also the breastfeeding dyad, must be a priority for those concerned with the right to food.

\footnotetext{
${ }^{1}$ Consider, by contrast, the following statistic, "for every 3 million bottle fed babies, 450 million tins are discarded" (Van Esterik, 2013, p. 520)_ — to say nothing of the plastic bottles used for liquid formula.
} 
In moving past a "right to food" and towards a "right to feed," Van Esterik (1999b) argues that women across the world have a special relationship with food. While acknowledging that women's association with food is not their natural or essential function (p. 158), she notes that in many places a woman's self-identity is based on her ability to feed her family (p. 226), and this ability is a source of power and identity (p. 157). Undoubtedly, given the feminization of poverty and hunger worldwide, it is often also a source of strain. Thus food security should be a key component of any notion of women's rights. Van Esterik (1999a) thus proposes reintegrating gender into discussions of food security, primarily by moving away from the passive "right to be fed" and the "right to food" (which frames food as a product), to the right to feed, which emphasizes active agency-particularly of those whose efforts typically bring about the realization of the right to food: women and especially mothers (p. 228). This is particularly true in the case of breastfeeding mothers. Conversely, the right to feed could also be construed as agential from the baby's perspective-as baby’s demand increases supply, "the infant is actively empowered and “controls” its food supply” (Van Esterik, 2013, p. 520).

Both Van Esterik’s “right to feed” and De Schutter's “right to food” acknowledge that these rights cannot be realized in a vacuum, but are co-constitutive with other rights. De Schutter signals the co-constitutive nature of the right to food with other rights when he discusses poverty and lack of social protections as an impediment to food access:

Social protection plays an important role in improving food security. As such, establishing a comprehensive social protection system is one policy measure to enable the poorest and most disadvantaged to realize their right to adequate food, among other rights. (De Schutter, 2013, n.p.). For her part, Van Esterik (1999a) hits upon the co-constitutive nature of the right to food with other rights when she argues that women cannot care for others without enhancing their own status, including access to equity in wages, education and training, and other social services (p. 229). Both authors thus emphasize the deep interconnections amongst a broad set of economic, social and cultural (ESC) rights, and food-related rights, whether it be the right to food (De Schutter) or the right to feed (Van Esterik). In addition to these interconnected rights, I add children's internationally recognized right to health as one critical strand in the web of co-constitutive rights that must be considered in tandem with gendering food-related rights.

Article 24 of the Convention on the Rights of the Child asserts that every child has the right to the highest attainable standard of health. Section 2 (c) provides that all states shall take measures "to combat disease and malnutrition, including within the framework of primary health care.” Further, the Global Strategy for Infant and Young Child Feeding adopted by the World Health Organization (WHO) in 2002 "called for a revitalisation of the global commitment to appropriate infant and young child nutrition, and in particular breastfeeding and complementary feeding” (Eide \& Eide, 2006, p. 29). The remarkable powers of breastmilk justify its special standing in that class of goods that enhance child health and combat disease and malnutrition, including its role in reducing the occurrence of serious illness such as necrotizing enterocolitis (Sullivan et al., 2010), increasing immunological resistance (Field, 2005), cultivating a healthy microbiome (Albenberg \& Wu, 2014), preventing otitis media 
(McNiel, Labbok, \& Abrahams, 2010, p. 51-52) and its soporific effects (Engler et al., 2012; Sánchez et al., 2009), sometimes described colloquially as infants being "milk drunk." Given its importance, and its recognition in already-existing international human rights law, it is right to acknowledge that breastmilk should be at the heart of efforts to achieve the highest attainable standard of health for children. However, reasons such as these have led some to claim that mothers have a "moral obligation" to nurse their babies_-implying that a baby's right to breastmilk might trump a mother's right to choose (for a careful treatment of this type of argument, see Overall \& Bernard, 2014).

While a mother has a moral obligation toward her child, it may be more parsimonious to claim that her duty, like that of all parents, is to do her best, whatever that may look like in a given circumstance. Since the nursing dyad necessarily consists of both child and mother, it is necessary to consider both the child and the mother's rights, and the possible implications of positing a right that baby holds against mother. On the basis that this is not achievable, and because society as a whole is responsible for actively undermining breastfeeding in numerous ways, mothers should not be treated as solely responsible for fulfilling a child's health-related right to breastmilk or the highest quality alternative. Society generally, and the state in particular, must put in place standards that make breastfeeding or access to breastmilk a realistic option. Mothers should have access to a variety of supports, falling under ESC rights, which facilitate breastfeeding as an option. In the following section, I consider some ways in which societies currently undermine breastfeeding. Considering alternatives to these barriers allows us to reflect on ways forward.

\section{Social and economic barriers to breastfeeding}

There are a number of employment, socio-economic, and community health-related obstacles to meeting the breastfeeding ideal of "two years or beyond," as articulated by the WHO and by the Canadian Paediatric Society. Beginning with socio-economic barriers, extended, paid maternity leave is positively associated with breastfeeding initiation (Ogbuanu, Glover, Probst, Liu, \& Hussey, 2011, p. e1422). In Canada, only the most privileged of women who engage in paid work (which does not include self-employment) may be able to both qualify for, and afford, one year of paid maternity leave. Upon returning to paid work, many of the oft-stated advantages of breast-feeding, such as bonding and closeness to baby, convenience of avoiding bottles, and ondemand delivery of mother's milk disappear or reduce drastically. Many workplaces lack both spaces (including dedicated private, comfortable seating and fridges for milk storage) and builtin time (such as additional paid break time) for pumping or breastfeeding (Weber, Janson, Nolan, Wen, \& Rissel, 2011). This is linked to a further obstacle to continuing to provide breast milk after the return to work: the prevalence of work place culture that denies parenthood and normalizes single, unattached status. 
Hostility in the workplace to parenthood generally, and breastfeeding specifically, is communicated in various subtle and unsubtle ways. For example, the scheduling of meetings during evening hours or the expectation that emails and phone calls can be received and dealt with on evenings and weekends. Discussing the workplace as a space where men's experience is the norm, Caroline Jane Gatrell (2007) notes that among women she interviewed:

mothers were pressured by employers to return to work prematurely-looking and behaving just as they had before childbirth. Once back at work, mothers indicated that organisational aversion towards breastfeeding obliged them either to breastfeed and express milk in secret, or to disregard health guidance and their own wishes and stop breastfeeding (p. 398).

The demarcation of many workplaces as spaces where babies cannot be present usually leads to the forced separation of mothers from their babies (Hausman, 2004, p. 276). As suggested above, anticipation of this separation is associated with the decision not to initiate breastfeeding in the first place and to wean early (Weber et al, 2011, p. 1; Witters-Green, 2003, p. 418). In Canada, maternity leave is covered by Employment Insurance, which pays a portion of the individual's average weekly earnings. For women who are self-employed, have not worked for 600 insurable hours the previous year, or earn wages that are low to begin with even before subtracting a portion of them, maternity leave is simply out of reach. Women who do not have the opportunity to enjoy a maternity leave, or who have a very short leave, may find the hardest, initial work of initiating breastfeeding (establishing adequate milk supply, correcting latch, monitoring diapers for hydration, and waiting on an inefficient feeder) to be unworthy of the effort when they will have to return to paid work soon after. Extended maternity leave may be the best way around this (Hausman, 2004, p. 276), but in order to be a realistic possibility for most it would have to be well-paid leave.

Another barrier to breastfeeding is that in many jurisdictions women who struggle with breastfeeding must often take it upon themselves to seek out breastfeeding support, for example by attending support groups. This is likely to be difficult for rural women; women who live in communities where breastfeeding is unusual or stigmatized; or for single or low-income mothers who may lack a support person or wider support networks to help facilitate a visit to a support group or provide other forms of encouragement (Witters-Green, 2003, p. 419; also Chin \& Dozier, 2012). This is aggravated by wider societal pressure on women not to breastfeed publicly and the feelings of embarrassment and shame that many women experience when feeding their children in public (Taylor \& Wallace, 2012). For this reason, active outreach for all mothers that may include automatic home visits from lactation consultants and other support persons, on an opt-out basis, is a health-based intervention that could make a significant difference.

Another healthcare-related hindrance to breastfeeding is uneven knowledge of breastfeeding among healthcare professionals. Perhaps most significant here is the need for standardized and very thorough lactation education for physicians and other health care 
professionals - including and perhaps especially those who work outside of pediatrics. Women often encounter lack of support and inaccurate guidance related to physical breastfeeding challenges, and may ultimately lack faith in their physicians (Amir \& Ingram, 2008; Renfrew, 2006; Witters-Green, 2004, p. 417). Knowledge of breastfeeding and a supportive attitude among health care providers is thus a critical aspect of quality healthcare for women.

Human milk as a health issue also raises the matter of access for those who cannot produce milk and yet wish to nourish their child with it. Non-profit milk banks as a potential source of human milk hold promise, yet their number and accessibility, for potential users and donors alike, are limited. In Canada for instance, there are three milk banks, the easternmost is in Ontario (with a "milk room” at IWK Health Centre in Halifax containing donated milk that is pasteurized in Calgary). This leaves all of eastern Canada without the benefits of a milk bank. Increasing funding and service to existing non-profit milk banks and milk rooms, opening more milk banks, milk rooms and milk exchanges, and making it easier (while retaining safety standards) for donors would likely help communities to meet their ethical obligation to provide the best nutritional options to infants and children. Relatedly, pro-breastfeeding initiatives should acknowledge the potential presence of environmental toxins in water, cow milk, and human milk and create support for initiatives that attempt to curb and reduce toxic contamination of the environment (Boswell-Penc, 2006; Van Esterik, 2013, p. 520).

\section{Harmonizing our message: women's rights are food rights}

Given the host of societal barriers encompassing inadequate employment accommodation, maternity leave remuneration, lack of education, and health care deficiencies, positing a child's right to receive breastmilk from her or his mother is clearly insensitive to the realities that many mothers face. Alternatively, governments and communities can take measures to increase a child's likelihood of receiving breast milk (either from the child's mother or from donors) or an acceptable (highest quality) alternative should breastmilk not be an option. If, as I have argued above, children have the right to health, including appropriate nutrition encompassing breastfeeding and complementary feeding, this must include state and community-wide efforts to improve access to breastfeeding as a realistic option for all women and parents. Properly addressing these challenges, and fulfilling children's health-based rights, involves advocating interventions that increase women's enjoyment of a broad range of economic, social, and cultural rights that enhance their right to feed. This means that activism around food rights and food security must include in its mandate the following (but is not limited to these): transforming the workplace to be more inclusive; increasing economic supports (and social benefits) for pregnant women and mothers of infants; improving breastfeeding education for health professionals (and the community at large); and improving access to donor breastmilk. By targeting the state and communities as responsible for fulfilling these demands, attention is diverted away from mothers 
who are otherwise understood as individually responsible for saying “yes” to breastfeedingwhich usually amounts to a false choice.

Acknowledgements: I would like to thank Lincoln Addison, Sarah Martin, and three anonymous reviewers for discussing this article with me at various stages of its development and providing helpful feedback. Thanks also to the guest editors of this special issue for their correspondence.

\section{References}

Albenberg, L. G., and Wu, G. D. (2014). Diet and the intestinal microbiome: Associations, functions, and implications for health and disease. Gastroenterology, 146, 1564-1572.

Allen, J., \& Hector, D. (2005). Benefits of breastfeeding. New South Wales Public Health Bulletin, 16(3-4), 42-6.

Amir, L., \& Ingram, J. (2008). Health professionals' advice for breastfeeding problems: Not good enough! International Breastfeeding Journal, 3(22), 1-2.

Bartlett, A. (2005). Breastwork: Rethinking breastfeeding. Sydney: UNSW Press.

Boswell-Penc, M. (2006). Tainted milk: Breastmilk, feminisms, and the politics of environmental degradation. Albany: State University of New York Press.

Chin, N,, \& Dozier, A. (2012). The dangers of baring the breast: Structural violence and formula feeding among low-income women. In P. Hall Smith, B.L. Hausman, \& M. Labbok (Eds.), Beyond health, beyond choice: breastfeeding constraints and realities, (pp. 64-73). New Brunswick: Rutgers University Press, pp.64-73.

De Schutter, O. (2009). The right to food: Fighting for adequate food in a global crisis. Harvard International Review, 31(2), 38-42.

De Schutter, O. (2011a). The right of everyone to enjoy the benefits of scientific progress and the right to food: From conflict to complementarity. Human Rights Quarterly, 33(2), 304-350.

De Schutter, O. (2011b). The right to an adequate diet: The agriculture-food-health nexus. Report presented at the 19th session of the United Nations Human Rights Council, Geneva, Switzerland.

De Schutter, O. (2012). Report submitted by the Special Rapporteur on the right to food: Women's rights and the right to food, 24 December. (A/HRC/22/50). Retrieved from http://www.refworld.org/docid/511cae602.html 
De Schutter, O. (2013). Report of the Special Rapporteur on the right to food mission to Canada (DesLibris. Documents collection). New York, N.Y.: United Nations Human Rights Council.

Eide, A., \& Eide, W.B. (2006). Commentary on the United Nations Convention on the Rights of the Child, article 24: The right to health. The Hague: Martinus Nijhoff.

Engler, A.C., Hadash, A., Shehadeh, N., \& Pillar, G. (2012). Breastfeeding may improve nocturnal sleep and reduce infantile colic: potential role of breast milk melatonin. European Journal of Pediatrics, 171(4), 729-732.

Ertem, I.O., N. Votto \& J.M. Leventhal. (2001). The timing and predictors of the early termination of breastfeeding. Pediatrics, 107(3), 543-548.

Field, C. J. (2005). The immunological components of human milk and their effect on immune development in infants.” Journal of Nutrition, 135(1), 1-4.

Galtry, J. (1997). Suckling and silence in the U.S.A.: The costs and benefits of breastfeeding. Feminist Economics, 3(3), 1-24.

Gatrell, C. (2007). Secrets and lies: Breastfeeding and professional paid work. Social Science \& Medicine, 65(2), 393-404.

Guttman, N. and Zimmerman, D.R. (2000). Low-income mothers’ views on breastfeeding. Social Science and Medicine, 50(10), 1457-1473.

Hausman, B. (2004) The feminist politics of breastfeeding. Australian Feminist Studies, 19(45), 273-285.

Kukla, R. (2006). Ethics and ideology in breastfeeding advocacy campaigns. Hypatia, 21(1), 157-180.

Mcniel, M., Labbok, M., \& Abrahams, S. (2010). What are the risks associated with formula feeding? A re-analysis and review. Breastfeeding Review: Professional Publication of the Nursing Mothers’ Association of Australia, 18(2), 25-32.

Murphy, E. (2003). Expertise and forms of knowledge in the government of families. The Sociological Review, 51(4), 433-462.

Ogbuanu, C., Glover, S., Probst, J., Liu, J., \& Hussey, J. (2011). The effect of maternity leave length and time of return to work on breastfeeding. Pediatrics, 127(6), E1414-27.

Overall, C. \& Bernard, T. (2012). Into the mouths of babes: The moral responsibility to breastfeed. In S. Lintott and M. Sander-Staudt, (Eds.), Philosophical inquiries into pregnancy, childbirth, and mothering (pp. 49-63). New York: Routledge. 
Renfrew, M.J. (2006). Time to get serious about educating health professionals. Maternal Child Health, 2(4), 193-195.

Sánchez, C.L., Cubero, J., Sánchez, J., Chanclón, B., Rivero, M., Rodríguez, A.B. \& Barriga, C. (2009). The possible role of human milk nucleotides as sleep inducers. Nutritional neuroscience, 12(1), 2-8.

Sullivan, S., Schanler, R.J.. Kim, J.H., Patel, A.L., Trawöger, R., Kiechl-Kohlendorfer, U. ... Lucas, A. (2010). An exclusively human milk-based diet is associated with a lower rate of necrotizing enterocolitis than a diet of human milk and bovine milk-based products. Journal of Pediatrics 156(4), 562-567.

Taylor, E.N. \& Wallace, L.E. (2012). For shame: feminism, breastfeeding advocacy, and maternal guilt. Hypatia, 27(1), 76-98.

Van Esterik, P. (1999a). Right to food; right to feed; right to be fed. The intersection of women's rights and the right to food. Agriculture and Human Values, 16(2), 225-232.

Van Esterik, P. (1999b). Gender and sustainable food systems: A feminist critique. In Koç, M., MacRae, R., Mougeot, L.J.A. \& Welsh, J. (Eds.), For hunger-proof cities: Sustainable urban food systems (157-161). Ottawa: International Development Research Centre.

Van Esterik, P. (2013). The politics of breastfeeding: An advocacy update. In Counihan, C. (Ed.), Food and culture: A reader, 3rd Edition (pp. 510-530). London: Routledge.

Weber, D, Janson, A., Nolan, M., Wen, L.M., \& Rissel, C. (2011).Female employees’ perceptions of organisational support for breastfeeding at work: Findings from an Australian health service workplace. International Breastfeeding Journal, 6(19), 1-7.

Witters-Green, R. (2013). “Increasing Breastfeeding Rates in Working Mothers.” Families, Systems \& Health, 21(4), 415-434. 